\title{
Retrieval of a large resected specimen using a large-caliber cap after colorectal endoscopic submucosal dissection
}

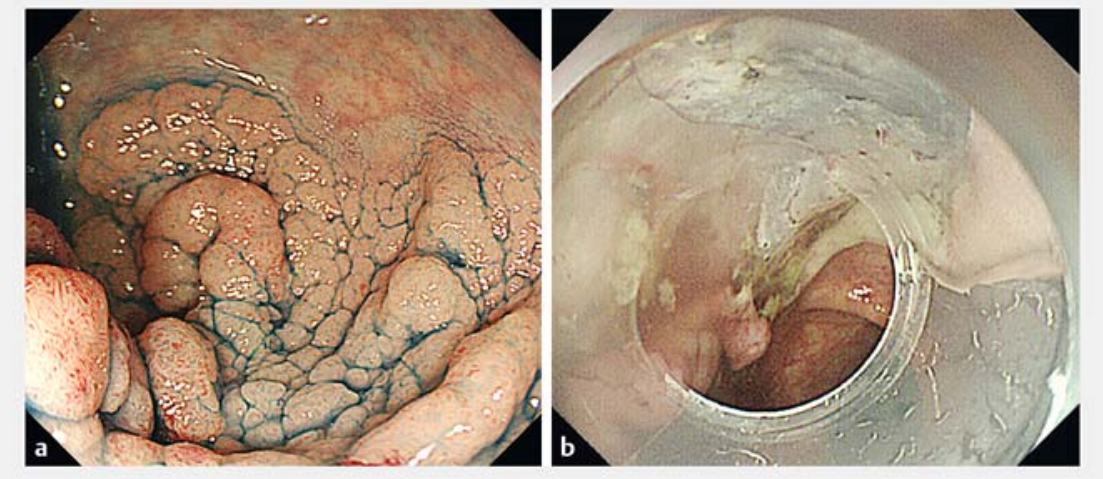

- Fig. 1 Large tumor located in the rectosigmoid colon. a Overview of the tumor. b The cap is a large-caliber device; however, it can be inserted easily through the anal canal because the cap is transparent, oblique, and soft.

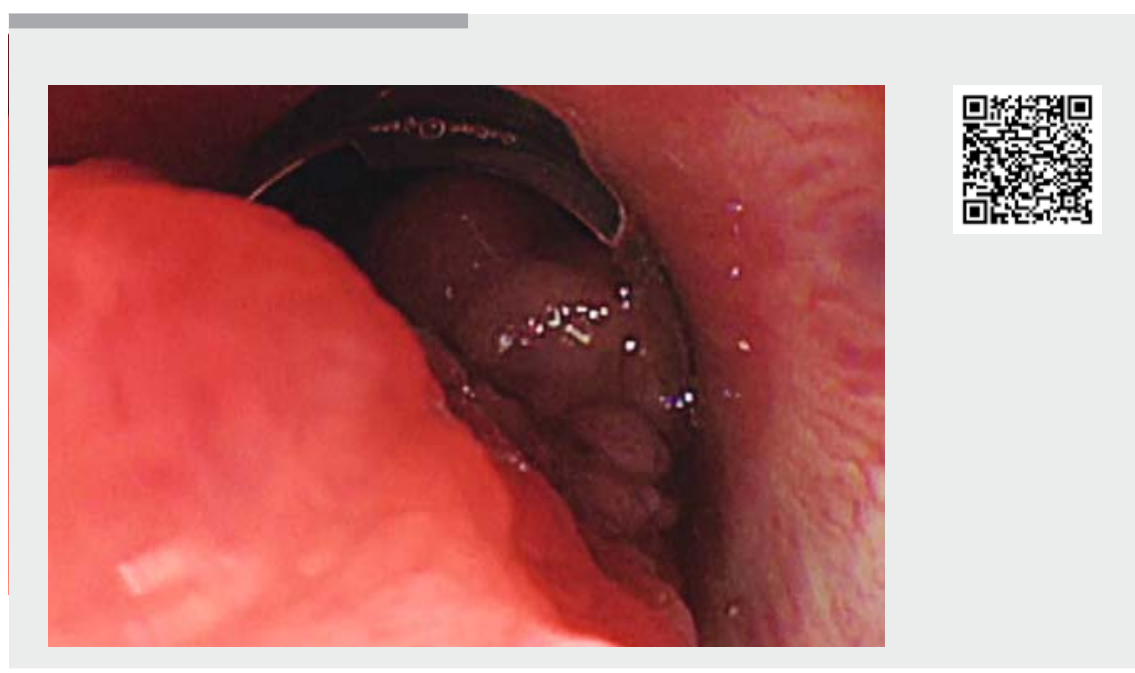

$\square$ Video 1 Retrieval of a large resected specimen using a large-caliber cap after colorectal endoscopic submucosal dissection.

Endoscopic submucosal dissection (ESD) has emerged as a feasible treatment option for colorectal tumors [1]. However, large colorectal specimens obtained via ESD that are difficult to retrieve from the anal canal are often encountered. We have experienced a few cases of specimen fragmentation during retrieval. Precise histological evaluation requires an intact specimen and fragmentation should be avoided. Several recent re- ports have described useful techniques for the retrieval of intact resected specimens [2-4]; however, these reported methods are relatively complex. We describe a more convenient and easy way of retrieving resected specimens using a large-caliber cap.

The first case involves a 73-year-old man who underwent ESD for a large laterally spreading tumor (LST) located in the rectosigmoid colon ( $\triangleright$ Fig. 1 a). We removed

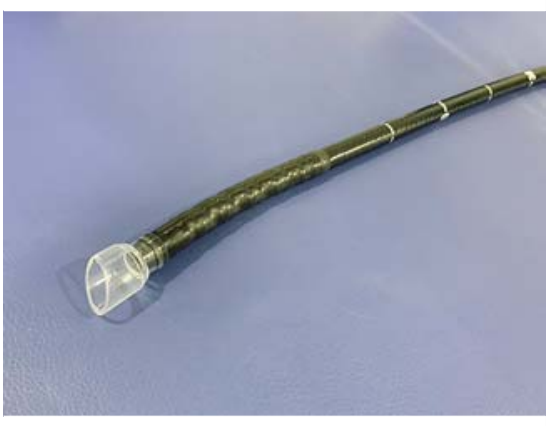

- Fig. 2 Large-caliber (outer diameter $18 \mathrm{~mm}$ ) oblique soft cap (D-206; Olympus, Tokyo, Japan) was placed on the tip of the endoscope.

the tumor via en bloc resection using a DualKnife (Olympus, Tokyo, Japan) and a short-type small-caliber-tip transparent cap (Fujifilm, Tokyo, Japan). Because the resected specimen measured over $10 \mathrm{~cm}$, its retrieval from the anal canal was very difficult. Therefore, a large-caliber (outer diameter $18 \mathrm{~mm}$ ) oblique soft cap (D-206; Olympus) for cap-assisted endoscopic mucosal resection [5] was placed on the tip of the endoscope ( $\triangleright$ Fig. 2). We suctioned the resected specimen into the cap and retrieved it easily from the anal canal ( $\triangleright$ Fig. 1 b, $\triangleright$ Video 1 ). Because the cap could pass through the anal canal while protecting the resected specimen, the resected specimen did not fragment. Precise histological evaluation revealed negative margins.

The second case involved a 68-year-old man who underwent ESD for a large LST located in the upper rectum ( $\triangleright$ Fig. 3 a). The tumor was removed via en bloc resection, and was easily retrieved using the same method as that described above ( $\triangleright$ Fig. $\mathbf{3}$ b, $\triangleright$ Video 1 ).

Since 2014, we have used this method to successfully retrieve specimens measuring over $50 \mathrm{~mm}$ without fragmentation, regardless of tumor shape.

Endoscopy_UCTN_Code_TTT_1AQ_2AD 

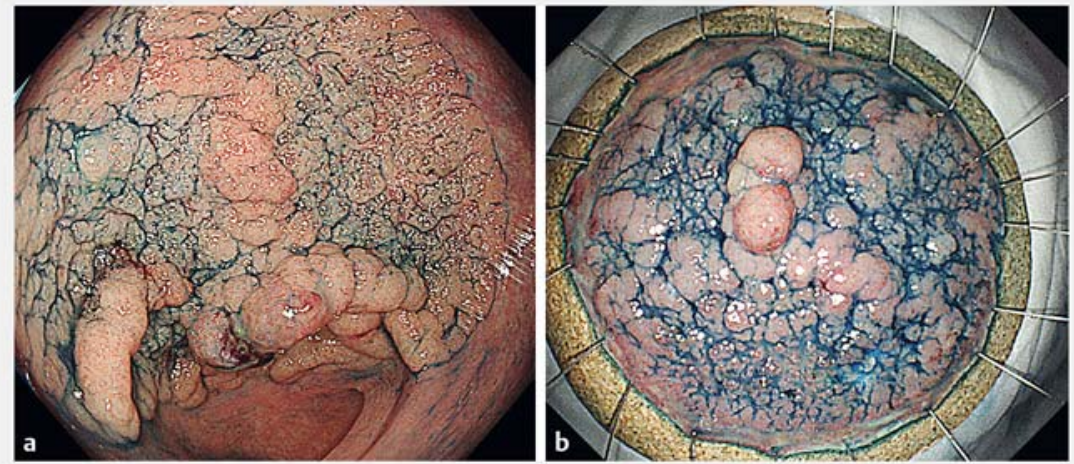

Fig. 3 Large tumor located in the upper rectum. a Overview of the tumor. b Resected specimen. Histological evaluation revealed that the cut margins were negative for intramucosal cancer.

\section{Competing interests}

None

The authors

Yuichiro Kuroki, Kunio Asonuma, Natsumi Uehara, Toshiyuki Endo, Reika Suzuki, Yorimasa Yamamoto, Masatsugu Nagahama Department of Gastroenterology, Showa University Fujigaoka Hospital, Kanagawa, Japan

\section{Corresponding author}

\section{Yuichiro Kuroki, MD}

Department of Gastroenterology, Showa University Fujigaoka Hospital, 1-30

Fujigaoka, Aoba-ku, Yokohama 227-8501, Japan

Fax: +81-45-9713824

yu-kuroki@med.showa-u.ac.jp

\section{References}

[1] Saito Y, Yamada M, So E et al. Colorectal endoscopic submucosal dissection: technical advantages compared to endoscopic mucosal resection and minimally invasive surgery. Dig Endosc 2014; 26: $52-61$

[2] Ikehara H, Saito Y, Uraoka T et al. Specimen retrieval method using a sliding overtube for large colorectal neoplasm following endoscopic submucosal dissection. Endoscopy 2015; 47: E168 -E169
[3] Nemoto D, Hayashi Y, Utano K et al. A novel retrieval technique for large colorectal tumors resected by endoscopic submucosal dissection: tumor extraction by defecation. Endosc Int Open 2016; 4: E93 - E95

[4] Tanaka S, Toyonaga T, East J et al. Endoscopic retrieval method using a small gripseal plastic bag for large colorectal resection specimens after endoscopic submucosal dissection. Endoscopy 2010; 42: E186E187

[5] Inoue H, Endo M, Takeshita K et al. A new simplified technique of endoscopic esophageal mucosal resection using a cap-fitted panendoscope (EMRC). Surg Endosc 1992; 6: $264-265$

\section{Bibliography}

DOI https://doi.org/10.1055/a-0915-1785

Published online: 23.5.2019

Endoscopy 2019; 51: E299-E300

(C) Georg Thieme Verlag KG

Stuttgart · New York

ISSN 0013-726X

\section{ENDOSCOPY E-VIDEOS}

https://eref.thieme.de/e-videos

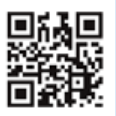

Endoscopy E-Videos is a free access online section, reporting on interesting cases and new techniques in gastroenterological endoscopy. All papers include a high quality video and all contributions are freely accessible online.

This section has its own submission website at

https://mc.manuscriptcentral.com/e-videos 